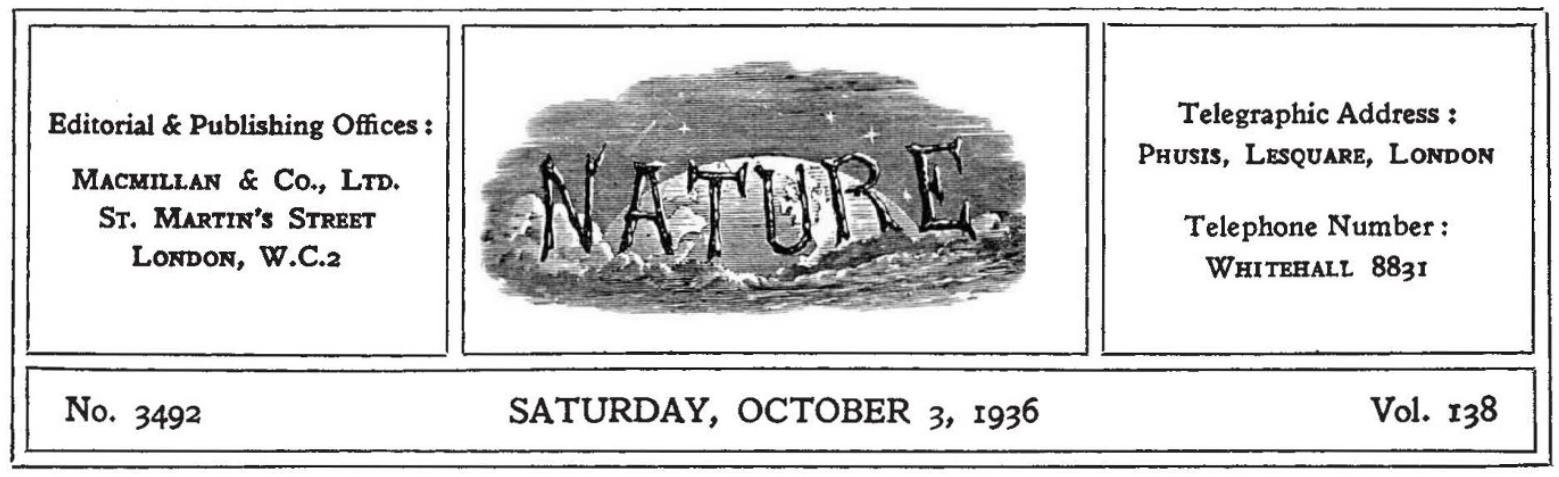

\title{
Leadership in Industry
}

$\mathrm{T}$ $\mathrm{HE}$ wide attention now being given to training for management in industry is indicated by the discussion in Section F (Economics) of the British Association at the recent Blackpool meeting on the subject. This interest finds ample justification in a pregnant passage in the introduction to the recent annual report of the Industrial Health Research Board. The aim of the research work directed by the Board is to advance knowledge which may be used in the prevention of industrial misfits, the complex causes of which offer a wide field for investigation. While many factors enter into industrial fitness, advancing knowledge now offers the prospect of being able to lay down, though not rigidly, reasonable physical and mental standards for various occupations which should ensure for the operative entering industry a greater chance of maintaining good health, in the broadest sense of the word, during his working life.

Given, however, the best conditions of work and the most carefully selected body of employees, the final responsibility for the maintenance of health and contentment lies with the supervising staff. Accordingly, the greatest practical contribution of vocational tests to industry would be proof of their value in selecting such staff, from foremen to managers.

Scientific and technical matters are nevertheless not the only factors which increase the onus and responsibilities of management. The very demand of industry for alert, smart, active men, rather than men of brawn and muscle, brings fresh problems. While such men are more adaptable to the needs of modern industry, they are also more responsive to variations in their environment, more aggressive, quicker to make trouble, and to demand their rights, as well as more liable to forget their duties. Thus, as the Report points out, the modern manager of a labour force must be awake to the changes, physical and mental, which are taking place. He can no longer be a dictator or afford to be tactless.

Many of the investigations of the Industrial Health Research Board point to the conclusion that selection and training are especially needed for management. Corroborative evidence is provided by those passages of the recent report of H.M. Chief Inspector of Factories, in which reference is made to the opportunity of improvement in regard to the prevention of accidents in the education of the smaller and often non-associated employers.

The rising accident incidence rates among young workers affords another illustration of the extent to which scientific management has still to make its influence felt in industry. Similarly, the existence of gross overwork reported under hours of employment further indicates the many problems, such as the extension of the five-day week or the two-shift system, which call for scientific assistance both in the investigation and in the application of the results obtained.

If the importance of training for management is now fully realized in many quarters, the practical question of how such training is to be given is far from being solved, as the discussion at Blackpool referred to above clearly showed. Already academic courses of study are prolonged, and with their crowded time-tables tend to inculcate ready-made ideas without sufficient stress being laid upon a general background of fundamental natural laws, so that the average student readily loses his sense of individuality and the desire for original thought. 
Merely to add a further course of lectures or classes to an overcrowded syllabus is unlikely to assist either the undergraduate or the young graduate to qualify for positions of responsibility in which clarity of judgment, a sense of values, and a knowledge of fundamental principles are among the first qualifications demanded.

In a valuable paper on accident prevention in industry, contributed to the Chemical Engineering Congress of the World Power Conference last July, Messrs. C. S. Robinson and H. R. Payne pointed out, for example, that most young technical men take up their first post in a works without having heard of accident prevention during their academic careers. Accordingly, in their keenness on their work they were liable, through inexperience, to endanger at first the safety traditions which their employers had been at pains to establish. Messrs. Robinson and Payne suggest accordingly that there is scope for the inclusion of accident principles in the training given to men destined for executive work in manufacturing industries.

This, of course, is not to suggest that training in accident prevention should be included in the curriculum of the university or technical college. It is rather a definite plea for closely thought out plans of training for all those entering the management or executive side of industry. The most important contribution which the university could make in this field is probably that of stripping its courses of study so that they stimulate originality and initiative. If, by divesting the syllabuses of much of their minutiæ, concentrating on the fundamental principles and leaving the student adequate time to think for himself, the university can supply recruits for industry who are characterized less by knowledge of unassimilated facts than by their grasp of principles, freshness of outlook and capacity for independent and critical thought, the most important first step in training for management will have been taken.

From such recruits, the training courses which many industries normally give will enable the more promising material to be sifted readily, while the general standard of assimilation and adjustment to the industry's requirements will be considerably raised. The question of further training and selection remains. Whether it is best to recruit a specially selected small group of individuals, providing them with special opportunities for acquiring experience, and promoting them rapidly as occasion offers to the higher administrative posts, is at least debatable. Fre- quently administrative ability, even of the highest order, develops only with experience, and accordingly it is of advantage to select staff for training for promotion to the highest positions of management not from the recruits entering the organization, but from those of a few years' service, whose record indicates sufficient promise.

For such promising employees some firms have used the Department of Business Administration at the London School of Economics as a kind of staff college, to give them a wider view of their work. The combination of training of this type, either external or, with the larger firms, internal, with the provision of special opportunities for acquiring experience for those whose ability has been further demonstrated in the training course, appears to offer special promise. There still remains, however, the necessity for the chief executives of the firm to devote their own time to the training of those destined to occupy the higher positions, and upon the quality and thoroughness of this training at present as much depends as on anything else.

The problem is, in fact, only partly that of recruiting the right type of material and providing the promising recruit with opportunities for sufficiently rapid promotion. It is also that of securing in the organization the tradition and atmosphere in which efficient management is possible. The highest possible type of recruit will prove largely ineffective if sound principles of business management are continually being violated in the organization, whether on the plea of privilege or expediency or anything else. Indifference to such matters undermines the efficiency of many firms to-day, and is a fatal obstacle in building for to-morrow an alert and efficient management competent to assess the many intricate factors involved, and to meet with knowledge and resource the ever-changing conditions of industry.

For this reason, the continued penetration of the professional spirit in the sphere of manage. ment, with its sense of social and professional responsibility and insistence on the linking of action to facts, is highly important. Even yet the lessons of the industrial revolution of the last century and more are largely unlearnt, and machinery tends to be our master and not our servant. Only as something of the scientifie spirit takes charge, seeking to develop methods which eliminate the loss and inefficiency in the sphere of human or social relations and distribution, 
which have so far largely annulled or even out. weighed the advantages which have come from the greater mechanical efficiency of power production and modern machinery, can we hope for the evolution of organization in which the machine is assimilated to human purposes.

The management of to-morrow cannot be content to think of efficiency in terms of mechanical and physical production alone. As Sir Josiah Stamp's presidential address at Blackpool suggests, it must take account of the direct and indirect consequences of mass production, monotony of work, nervous tension, leading to mechanization of mind and diminished creative power. In the narrowest sense, industrial efficiency cannot long be maintained at a high mechanical level if the social efficiency of the worker or consumer is low. Here, as much as in the field of distribution, are questions calling for close investigation if we are to evolve an industrial and social order in which the possibilities of higher standards of living now within our reach through power production are really utilized.

The fundamental demand, therefore, in industry as elsewhere, is for those who can bring to these problems of administration minds not only capable of grasping all the relevant facts and assessing values accurately, sympathetically and impartially, but also imaginatively alive to the future possibilities and free from the bondage of past traditions, whether in the economic or any other sphere. No less in the industrial than in the political world the creative mind is required, ready to adventure and experiment in a scientific spirit, unhampered by outworn conventions and traditional practices.

\section{The Early Cultures of China}

The Birth of China:

a Survey of the Formative Period of Chinese Civilization. By Herrlee Glessner Creel. Pp. $396+16$ plates. (London: Jonathan Cape, Ltd., 1936.) 15s. net.

IT may seem remarkable that the Chinese with I their passion for 'antiques' should have neglected their antiquities. The reason is not far to seek. Their intense interest in the past has been æsthetic and ethical, rather than archæological : chefs d'œurre of art and literary sources, especially those of a philosophical cast or concerned with great personalities, exclusively absorbed their attention. In this we should be the last to blame them, for the history of study of the past in China runs closely parallel with that of similar studies in Britain. When once the researches of foreign scholars and students of geology, palæontology and anthropology had laid open other fields to their interest, the national pride in Chinese culture turned to research and exploration in the field. Since 1927, the National Institute of Research in History and Philology has pursued a policy of conservation and investigation, of which the remarkable results achieved recently in Chinese pre-history and history are presented in Dr. Creel's "The Birth of China".

In 1921 Dr. J. Gunnar Andersson, then attached to the Chinese Geological Survey, began an archæological exploration of northern China, which has now produced evidence of a neolithic culture on a large number of sites. One of the earliest and most interesting results to emerge was the existence there of a painted pottery of the highest quality, comparable to the painted pottery which had been found in western Asia, now known to be characteristic of a chalcolithic civilization and to extend from southern Russia to northern China. Further research, as yet, has by no means solved the problem of the relation of the Chinese neolithic culture with the West, nor has its internal development been fully demonstrated. The finds hitherto are regarded as late; but of these, what is apparently the earliest phase is characterized by a greyish coarse ware, which is followed by the culture of the painted pottery, presumably intrusive, but with a local centre of diffusion in north-west China. The painted pottery in its turn is followed by a 'black pottery culture', of which the first indication was found in Shantung in 1930 and 1931. Certain elements peculiar to China, and appearing more or less constantly throughout the neolithic, point to a certain continuity of culture, but the 'black pottery culture' introduces elements which are new to China, while its resemblances to later developments, notably in pottery technique, make it something of a connecting link between the earlier neolithic and the succeeding bronze age cultures.

Archæologists in Europe have had little opportunity of studying in detail the great development in the study of the civilization of the bronze age which has followed on the excavations of the National Institute of Research since 1928 at Anyang in northern Honan, North China. Indeed, the 